Review

\title{
Comparative analysis of triage systems at emergency departments of different countries: Implementation in Kazakhstan
}

\author{
Lyudmila Pivina ${ }^{1}$, Assylzhan M. Messova ${ }^{1}$, Yersin T. Zhunussov ${ }^{1}$, Zhanar Urazalina ${ }^{1}$, Zhanna Muzdubayeva ${ }^{1}$, \\ Diana Ygiyeva ${ }^{1}$, Murat Muratoglu ${ }^{2}$, Gulnara Batenova ${ }^{1}$, Sharbanu Uisenbayeva ${ }^{1}$, Yulia Semenova ${ }^{1}$ \\ ${ }^{1}$ Semey Medical University, Semey, Kazakhstan \\ ${ }^{2}$ Bashkent University, Ankara, Turkey
}

Received 19 May 2021, Revised 28 June 2021, Accepted 9 July 2021

(C) 2021, Russian Open Medical Journal

\begin{abstract}
Medical sorting is aimed at assessment of disease severity and has to be carried out within a short time to determine the priorities for patient care and transportation to the most appropriate place for future treatment. The goal of this study was to provide an integrative review by analyzing the publications on the most common triage systems worldwide in order to select and implement the most reliable system at emergency departments. We searched for publications relevant to our comparative analysis in evidence-based medicine databases. A total of 1,740 literary sources were identified, of which 42 were selected for analysis. Comparative analysis of different triage systems may help implementing the most efficient system in Kazakhstan. The Emergency Severity Index is considered the most reliable and accurate tool used in international practice, and it could provide a basis for introduction of triage system at emergency departments in Kazakhstan.
\end{abstract}

Keywords: triage, emergency department, five-level triage, triage scale.

Cite as Pivina L, Messova AM, Zhunussov YT, Urazalina Z, Muzdubayeva Z, Ygiyeva D, Muratoglu M, Batenova G, Uisenbayeva S, Semenova Y. Comparative analysis of triage systems at emergency departments of different countries: Implementation in Kazakhstan. Russian Open Medical Journal $2021 ; 10$ : e0301.

Correspondence to Assylzhan Messova. Phone: +77772138307. E-mail: assylzhan2006@mail.ru.

\section{Introduction}

A system for prioritizing treatment of patients based on the severity of their condition (triage) is essential for provisioning an inpatient emergency care. The emergency department is an important link between the ambulance service and the hospital. Currently all countries face increase in the number of patients visiting emergency departments, which provide them with primary access to a health care system [1]. This situation is explained by the lack of clinical guidelines developed for management of emergency pathologies at the preclinical stage [2]. The number of patients admitted to emergency departments cannot be predicted with great precision; and only a fraction of those suffers from lifethreatening diseases or conditions requiring urgent care [3], and not all patients are in need of immediate medical care. Therefore, patients with severe pathologies and life-threatening injuries should be identified within minutes of their admission to emergency departments [4]. At emergency departments, triage is aimed at assessing the severity of illness or injury, prioritizing care and transporting the patient to the most appropriate location for the subsequent treatment $[5,6]$. Only the use of a valid and reliable triage system, based on world experience, could help ensuring the most timely and adequate treatment, to shorten the length of a hospital stay, which, in turn, could increase the costeffectiveness of diagnosis and treatment. An effective triage system is of particular importance in the context of mass disasters and epidemics, such as the COVID-19 pandemic. Currently, an emergency department serves the main link in triage for this infection.

In post-Soviet countries, including Kazakhstan, the sorting algorithm is based on the principles of military surgery, which are relevant for massive wounds received during wars, accidents and disasters. There is no single triage system at emergency departments yet; in each hospital, triage is carried out using locally developed algorithms. Recently, the problem of triage has become more and more urgent due to a change in the demographic structure of the population with an increase in the proportion of elderly people, and growing prevalence of obesity, diabetes and other chronic non-communicable diseases. All these categories of patients tend to be admitted for hospitalization quite frequently, which leads to overcrowding of emergency departments and creates difficulties for decision-making regarding the provisioning of a medical care. Training of professionals in emergency medicine has started in Kazakhstan only in 2018, and in 2019, the residency program was opened. Lack of emergency clinicians, trained nurses, and medical professionals is associated with additional obstacles for triaging of patients in need of an emergency care.

The goal of this study was to provide an integrative review via analyzing the publications on the most common triage systems worldwide in order to select and implement the most reliable system at emergency departments in the Republic of Kazakhstan. 
Table 1. Characteristics of the most prevalent international five-level triage systems used at emergency departments

\begin{tabular}{|c|c|c|c|c|}
\hline Rates & ATS & MTS & CTAS & ESI \\
\hline Time before primary evaluation of a patient status & 10 min. & Not indicated & Not indicated & Not indicated \\
\hline Time before attendance by a physician & $\begin{array}{l}\text { Immediately/ } \\
10 / 30 / 60 / 120 \text { min }\end{array}$ & $\begin{array}{l}\text { Immediately/ } \\
10 / 60 / 120 / 240 \mathrm{~min}\end{array}$ & $\begin{array}{l}\text { Immediately/ } \\
15 / 30 / 60 / 120 \mathrm{~min}\end{array}$ & $\begin{array}{l}\text { Immediately/ } 10 \text { min, then it is not } \\
\text { indicated }\end{array}$ \\
\hline Physician examination during defined time & $\begin{array}{l}I-97,5 \% ; \text { II }-95 \%, I I I- \\
90 \% ; I V-90 \%, V-85 \%\end{array}$ & Not indicated & $\begin{array}{c}I-98 \% ; \text { II }-95 \%, \text { III }-90 \% ; \text { IV - } \\
85 \%, V-80 \%\end{array}$ & Not indicated \\
\hline Repeated triage & Not indicated & On demand & $\begin{array}{l}\text { I- long; II }-15 \mathrm{~min}, \mathrm{III}-30 \\
\mathrm{~min} ; \mathrm{IV}-60 \mathrm{~min} ; \mathrm{V}-120 \mathrm{~min} .\end{array}$ & On demand \\
\hline Pain scale & 4 items & 3 items & 10 items & $\begin{array}{l}\text { Visual Analog Scale (10 items, }>7 / 10 \\
\text { means the patient's severity level } 2\end{array}$ \\
\hline & & & & Considered for differentiation \\
\hline Pediatric case & Considered & Considered & Separate version of CTAS & $\begin{array}{l}\text { between ESI } 2 \text { и ESI 3, criteria for fever } \\
\text { in the children aged < } 24 \text { months. }\end{array}$ \\
\hline List of diagnosis or key symptoms & Present & 52 key symptoms & Present & Absent \\
\hline Implementation/educational materials & Limited & Present & Present & Present \\
\hline
\end{tabular}

ATS, Australian Triage Scale; CTAS, Canadian Triage and Acuity Scale; MTS, Manchester Triage System; ESI, Emergency Severity Index; I-V, triage levels.

\section{Materials and Methods}

The search for relevant scientific publications for the comparative analysis was carried out in evidence-based medicine databases (PubMed, Cochrane Library, Google Academy, ResearchGate), and those published over past 20 years were of interest to us. The following search filters or inclusion criteria were used: studies performed on people, published in English or Russian, and full versions of the articles. Preference was given to the studies of high methodological quality (meta-analyses, systematic reviews and cohort studies), in the absence of which the studies of lower methodological quality were taken into account. We used the following keywords: triage AND emergency department (number of publications ( $\mathrm{n}$ ) was equal 1,587); fivelevel triage $(n=25)$; Canadian Triage and Acuity Scale $(n=40)$; National Triage Scale $(n=17)$; Australasian Triage Scale $(n=30)$; Manchester Triage System ( $n=15)$; and Emergency Severity Index $(n=26)$. We removed 618 duplicate records; 1,062 records were excluded due to the lack of desirable information, unavailability of full texts, or usage of languages other than English or Russian. Forty-four publications out of 1,740 were selected for the subsequent analysis.

Each article was analyzed for the effectiveness, reliability and validity of individual triage systems. In addition, we analyzed such indicators as time prior to primary evaluation of a patient status, time before attendance by a physician, physician examination during defined time, necessity of repeated triage, relevance of pediatric case, type of pain scale, list of diagnoses or key symptoms, and presence of implementation/educational materials (Table 1).

\section{Results}

The medical sorting of patients at the hospital level requires the development of accurate standardized criteria for evaluation of clinical and economic efficiency, safety, and accessibility of a timely medical care. The most reliable and extensively used worldwide triage systems are the Canadian Triage and Acuity Scale, Emergency Severity Index (system based on the definition of the severity index in emergency conditions), Australian Triage Scale, and the Manchester triage system [6, 7].

The analysis of the literature data reveals the availability of various approaches and the systems for triaging the patients requiring an emergency medical care. The main criteria to determine the severity status are ability to move and respond to stimuli; presence of acute respiratory failure or respiratory distress syndrome, and acute cardiovascular failure; coma score sensu the Glasgow scale; evaluation of major vital signs, such as pulse on the radial artery, restoration of capillary filling, etc. [6]. In order to identify patients in critically serious conditions, it is not enough to just register the vital signs, which could be normal due to compensatory abilities [8]. Therefore, to determine priorities of treatment, we could use various international systems ranging from unstructured classification ('correct assumption' based on experience) [9], a three-level 'traffic light' system (red for expressed emergency, yellow for emergency, green for non-urgent cases [10] to four-level (or five-level) scales [11-12]. Five-level tools correlate significantly with use of resources, hospitalization rates, duration of emergency treatment, and frequency of hospitalization to intensive care units or mortality rates. Comparison of different triage methods showed that the three-level system has insufficient reliability, therefore only papers describing five-level triage systems were included in this review [6].

Limitation of resources and unpredictable fluctuation of demands are the main problems of medical sorting and emergency care at the hospital stage. It is expected that hospitals could be able to maintain functionality up to 96 hours without external resources - but in order to remain functional, hospital systems should increase available resources or to find ways for their effective redistribution. Reverse triage is a way of reorienting hospital resources in critically ill patients by identifying and discharging patients who have a relatively small risk of complications [13]. The most difficult problem in the provisioning medical care is triaging of elderly patients (due to large number of comorbidities, atypical clinical manifestations and presence of complications) $[6,14]$.

The most well-known system for determining the emergency severity index (ESI) is a five-level triage algorithm developed in the late 1990s in the United States [15, 16]. ESI is an easy sorting algorithm that classifies patients according to severity of their condition and resource requirements $[17,18]$. The algorithm for determining ESI usually includes four points for decision making: whether a patient is dying; whether a patient could wait for medical assistance; how much resources are needed to assist a patient and what are the vital signs of a patient? When a patient 
condition is life-threatening, the sorting process should be completed, and the patient is automatically referred to the first ESI level. In addition, level 1 is determined in the case of severe respiratory distress syndrome, the need for immediate airflow restoration, unconsciousness, absence of pulse, and a decrease in Sp02 to $<90 \%$. Second ESI level is defined when a patient cannot wait for medical care, if there is a high risk of life-threatening disorders of consciousness (confusion, drowsiness, disorientation), or a severe pain syndrome. High risk means a condition, which may quickly deteriorate, or a condition requiring an emergency treatment. Level $2 \mathrm{ESI}$ is observed in $25-35 \%$ of all patients at emergency departments; $50-60 \%$ of those could be hospitalized, and many of them could need intensive care in the nearest future. It is assumed that patients of the third ESI level require two or more resources for their treatment, and patients of the fourth ESI level need only one resource. Patients of the fifth ESI level do not require any resources; they should receive an outpatient medical assistance [19-23].

An objective assessment of a patient's main symptom is sometimes sufficient to categorize the severity level as high (levels 1 or $2 \mathrm{ESI}$ ) or low (levels 3, 4 or $5 \mathrm{ESI}$ ). However, the ESI Triage Research Team recommends estimating the full set of vital signs, including measurement of temperature, heart and respiratory rates, as well as a blood pressure. The severity of condition is determined by the indicators of vital functions and the potential threat to a patient's life $[6,19]$.

Vital signs are not always the most informative for determining the severity of the disease [19]. At least one study has shown that vital signs are not necessary on all occasions in order to provide an initial assessment of a patient under triage. In 2002, Cooper et al. studied the use of vital signs to evaluate a patient status. The final results showed that vital signs have changed the severity level in $8 \%$ of cases $[6,24,25]$

The Manchester Triage System (MTS) is used at emergency departments in the UK and Germany. It consists of 52 units based on the main symptoms [16]. The key parameters, such as threat to life, pain, or consciousness disorder are defined for each of these block diagrams [26-28]. This sorting system uses certain important indicators as discriminators in the current flowchart [28]. The effectiveness of this system was demonstrated in a 2012 retrospective cohort study aimed at assessment of the MTS accuracy at determining risks and priorities for the patient care within 24 hours of admission to emergency departments, which indicated that half of 139,000 patients were triaged within the recommended time (2-20 minutes), $88.4 \%$ of patients were not hospitalized, whereas $11.4 \%$ were hospitalized, and just $0.2 \%$ of cases were fatal $[6,29]$.

In Canada, the work of emergency departments is based on the use of Canadian Medical Triage and Acquired Scale (CTAS). This system categorizes both trauma and non-trauma cases and ranks them according to their severity from 1 to 5 points (where 1 is the highest one). This model provides a shared system of coordinates for both nurses and paramedics [30]. CTAS was introduced into a health care system in the 1990s [12, 31], and it primarily evaluates the time that passed from a patient admission to the examination by a doctor, assesses the clinical symptoms and signs in order to determine the severity level, including high risk of a lifethreatening condition [6].

Australian Triage Scale (ATS) has been used at all Australian emergency departments since 1994 [32]. Each level of severity has a certain time limit, during which a medical examination should be conducted. The information on how sorting process takes place in different hospitals and country regions is available online [6].

Comparative characteristics of the most common international five-level systems used at emergency departments are presented in the Table [6]. The time to an initial assessment of a patient's/victim's condition is indicated only in ATS, while the time from a patient's admission to attendance by the physician is clearly defined in each of the triage systems as level I severity (need for immediate examination). In the ESI system, the time of examination for a patient of levels II-V is not indicated at all. The duration of a patient examination is specified only in the ATS and CTAS. The time for repeated triage is clearly defined only in the Canadian system, in other systems it is conducted when needed. The Pain Self-Assessment Scale used in various systems ranges from 3 points in the MTS to 10 points in the ESI. All systems specifically consider triaging of children. Every system, except for ESI, contains a list of diagnoses or key symptoms for which a separate triage is performed. In ESI, such symptoms are indicated when determining the severity level of a patient.

Like Kazakhstan, Turkey is the country that started implementation of triaging with some delay. Effectiveness evaluation of triage system used in Turkey indicated the presence of some problems associated with overcrowding at emergency departments leading to extended wait for medical assistance. There is a need to combine the efforts of managers and medical staff from different departments in order to apply a multidisciplinary approach in the process of reducing the overcrowding at emergency departments [33-36]. To decrease the overcrowding at the Turkish emergency departments, Hacettepe University developed a symptom-based 5-level Hacettepe Emergency Triage System (HETS) based on ESI triage system. To develop this system, the main symptoms were analyzed, collected, and categorized into five triage levels based on the priority level and treatment provisioning. One hundred and twenty most common symptoms were distributed among triage levels [37].

In Kazakhstan, the triage of patients at emergency departments begins with registration, after which an emergency clinician estimates the severity of a patient's condition, investigates past history, and performs physical examination. Electronic patient files are used to reflect all types of preclinical care (in accordance with the standards for emergency medical care), and then the treatment is prescribed. If a patient's age is > 60 years or a patient has concomitant somatic pathology, he or she is consulted by an internist and/or cardiologist shortly after the admission [38].

\section{Discussion}

The need to triage the patients admitted to emergency departments is recognized throughout the world. Timely and correct distribution of patients among different groups, depending on their severity and the need for medical care, allows providing effective treatment of incoming patients, and also optimizing the activities provided by the medical staff. Introduction of a reliable triage system is among the priority tasks for public health in Kazakhstan.

Five-level triage systems can be considered a gold standard in providing emergency medical care around the world [6]. Since overcrowding of emergency departments takes place all over the world, various emergency triage systems have undergone through 
careful analysis, and Kazakhstan is no exception. Such systems as ATS, CTAS, MTS and ESI are among the most studied and widespread because they demonstrate a high level of validity and reliability [6]. However, the highest reliability, sensitivity and specificity were demonstrated by ESI and ATS triage systems. The 2017 Iranian study of children admitted to emergency departments disclosed high reliability of ESI system with a kappa of 0.65-0.92 ( $P<0.001)$, while ATS had a reliability with a kappa of $0.51-0.87$. ESI sensitivity and specificity ranged from $81-95 \%$ and $73-86 \%$, correspondingly. For ATS, these indicators ranged from $80 \%$ to $95 \%$ and from $74 \%$ to $87 \%$, respectively [39]. In another study, the ESI sensitivity was $89 \%$ (85-93\%), whereas the specificity was $97 \%(94-99 \%)$, with a positive predictive value of $68 \%$ (6274\%) [40].

The analysis of published data demonstrated the successful introduction of five-level triage systems, which are executed by specially trained nurses [6]. We are sure that such systems should be successfully used by medical staff in Kazakhstan to improve the quality of medical care at emergency departments. From 2018, the Kazakhstani nurses were trained for principles of triage at emergency departments.

At implementation of triage systems, special attention should be paid to the interdisciplinary approach to differential diagnosing, risk stratification and treatment algorithms for acute and emergency conditions, which should be reflected in the curricula of training programs. Experience of introducing the triage system in Australia has shown that it increased the patient safety, optimized the work of medical staff, and improved their job satisfaction. Besides, it reduced the waiting period between the hospital admission and examination by a physician, along with a length of a hospital stay. Moreover, the proportion of patients who left the waiting room without doctor's examination declined by $50 \%$, which improved their safety [3].

Some triage systems (CTAS, ATS, and MTS) have time limits in terms of attendance by a physician for a certain category of patients. The ESI system uses a different approach for patients of triage levels 3-5. In these cases, the goal is a prompt assessment of a patient condition, taking into account an existing workload of emergency department staff. Patients identified as level 1 priority should receive treatment immediately, and those who are classified as level 2 should receive immediate care by a nurse with continuous monitoring, and a doctor should examine such patient within a ten-minute period $[6,19]$.

The waiting time to the first attendance by a physician at an emergency department is one of the important indicators for any sorting system. In the CTAS system, the patient status is reassessed after a certain time to detect any deterioration as early as possible. ESI and ATS offer re-sorting only as needed (Table 1) [6]. Symptom-based 5-level Hacettepe Emergency Triage System, created for overcrowded emergency departments in Turkey, demonstrated a very good agreement with ESI system with minimal undertriage and overtriage rates. It is easily applied by emergency physicians, residents, interns and triage nurses.

Current model of emergency medical care in Kazakhstan, like the model used in the Russian Federation, belongs to the FrancoGerman (European) model of emergency care [41]. The staff of emergency departments in Kazakhstan is presented by surgeons, trauma specialists, internists, pediatricians and medical nurses. Other medical professionals, who are in charge of other inpatient departments, could also be involved in emergency care, if needed.
The assortment of such professionals usually includes an anesthesiologist, a neurosurgeon, a neurologist, an urologist, a cardiologist, a gynecologist, a vascular surgeon, a maxillofacial surgeon, and other specialists.

In Kazakhstan, the first steps to implementation of triage system were taken in 2018. According to the Decree of the Ministry of Healthcare, all patients at emergency department are supposed to be distributed between three areas. The green zone is envisaged for non-urgent patients when hospitalization is not needed. The patients not requiring emergent medical care, who can be admitted to the inpatient department, or remain under observation at the emergency department for several hours; or when clarification and differentiation are needed, are scheduled for the yellow zone. Meanwhile, the red zone is left for patients in need for immediate medical care within an emergency department [42]. Until now, all hospitals of Kazakhstan use a three-level triage system for patients, while five-level triage systems are considered to be the most reliable and accurate tools in international practice. The three-level system was introduced to emergency departments in Kazakhstan, considering the realities of existing health care system, as it is very simple and easy for understanding. However, since 2020, the Republic of Kazakhstan Ministry of Healthcare introduced the system of compulsory health insurance for country citizens, and it has become necessary to consider the availability of resources for provisioning the medical care. In this regard, we believe that introduction of ESI system would be the most appropriate and reflecting the available health care resources.

In our opinion, although the Kazakhstan system for emergency care experience a significant improvement over time, overcrowding at emergency department, along with the shortage of a specialized staff, remain the big challenges that need to be addressed in the nearest future. We still need to build capacities for appropriate interventions in multi-casualty incidents, disasters, pandemics, other special occasions (such as terrorist attacks); and also in chemical, biological, nuclear and radiological emergency situations.

Current uncertainties and difficulties in the system of medical care for patients in the context of the COVID-19 pandemic have led to the need of developing medical sorting algorithms for COVID-19 at various stages of medical care. Patients with COVID19 may also need emergency care. In a multidisciplinary hospital, the problem of medical sorting of patients to prevent the spread of COVID-19 is very acute, since the lack of clear and understandable sorting rules threatens to close the hospital and conduct quarantine measures, which would lead to the impossibility of providing medical care to patients even in emergency situations $[43,44]$.

\section{Study limitations}

There is a substantial deficiency of published data on the triage systems used in Kazakhstan. This is due to the fact that international triage systems are only beginning to be introduced in this country from 2017.

\section{Acknowledgements}

This research was conducted within the framework of the SHIP-2.3 / CS-1 project 'Methodological assistance in improving the training system for competitive specialists in the field of nuclear medicine and paramedicine', funded by the World Bank. 


\section{Conflict of Interest}

The authors declare that they do not have conflicts of interest.

\section{References}

1. Pitts SR, Niska RW, Xu J, Burt CW. National Hospital Ambulatory Medical Care Survey: 2006 emergency department summary. Natl Health Stat Report 2008; (7): 1-38. https://pubmed.ncbi.nlm.nih.gov/18958996.

2. Skjøt-Arkil H, Pontoppidan LL, Laursen JO, Giebner M, Andersen JD, Mogensen CB. Do prehospital providers and emergency nurses agree on triage assignment? Eur J Emerg Med 2017; 26(1): 29-33. https://doi.org:10.1097/MEJ.0000000000000503.

3. Marcin JP, Romano PS, Dayal P, Dharmar M, Chamberlain JM, Dudley $\mathrm{N}$, et al. Patient-level factors and the quality of care delivered in pediatric emergency departments. Acad Emerg Med 2018; 25(3): 301309. https://doi.org/10.1111/acem.13347.

4. Lombardo S, Unurbileg B, Gerelmaa J, Bayarbaatar L, Sarnai E, Price R. Trauma care in Mongolia: INTACT evaluation and recommendations for improvement. World J Surg 2018; 42(8):2285-2292. https://doi.org/10.1007/s00268-018-4462-8.

5. Fernandes CM, Tanabe $P$, Gilboy N, Johnson LA, McNair RS, Rosenau $\mathrm{AM}$, et al. Five-level triage: A report from the ACEP/ENA Five-Level Triage Task Force. J Emerg Nurs 2005; 31(1): 39-50. https://doi.org/10.1016/i.jen.2004.11.002.

6. Pivina LM, Alibaeva GA, Dyussupov AA, Aidossov NS, Messova AM, Urazalina $\mathrm{ZhM}$, et al. Principles of medical sorting of the patients at the hospital stage in emergency departments. Science \& Healthcare. 2018; 20(2): 115-128. https://doi.org/10.34689/SH.2018.20.2.010.

7. Kuriyama A, Urushidani S, Nakayama T. Five-level emergency triage systems: Variation in assessment of validity. Emerg Med J 2017; 34(11): 703-710. https://doi.org/10.1136/emermed-2016-206295.

8. Subbe CP, Slater A, Menon D, Gemmell L, et al. Validation of physiological scoring systems in the accident and emergency department. Emerg Med J 2006; 23(11): 841-845. https://doi.org/10.1136/emj.2006.035816.

9. Wuerz R, Fernandes CM, Alarcon J. Inconsistency of emergency department triage. Emergency Department Operations Research Working Group. Ann Emerg Med 1998; 32(4): 431-435. https://doi.org/10.1016/s0196-0644(98)70171-4.

10. Wuerz R, Travers D, Gilboy N, Eitel DR, Rosenau A, Yazhari R. Implementation and refinement of the emergency severity index. Acad Emerg Med 2001; 8(2): 170-176. https://doi.org/10.1111/j.15532712.2001.tb01283.x.

11. Bullard MJ, Musgrave E, Warren D, Unger B, Skeldon T, Grierson R, et al. Revisions to the Canadian Emergency Department Triage and Acuity Scale (CTAS) Guidelines 2016. CJEM 2017; 19(2): S18-S27. https://doi.org/10.1017/cem.2017.365.

12. Bullard MJ, Unger B, Spence J, Grafstein E; CTAS National Working Group. Revisions to the Canadian Emergency Department Triage and Acuity Scale (CTAS) adult guidelines. CJEM 2008; 10(2): 136-151. https://doi.org/10.1017/s1481803500009854.

13. Justice J, Walker, III JR. EMS Reverse Triage. 2021 Aug 11. In: StatPearls [Internet]. Treasure Island (FL): StatPearls Publishing; 2021. https://pubmed.ncbi.nlm.nih.gov/29489264.

14. Newgard CD, Yang Z, Nishijima D, McConnell KJ, Trent SA, Holmes JF, et al. Cost-effectiveness of field trauma triage among injured adults served by emergency medical services. J Am Coll Surg 2016; 222(6): 1125-1137. https://doi.org/10.1016/i.jamcollsurg.2016.02.014.

15. Wallis LA, Carley S. Comparison of paediatric major incident primary triage tools. Emerg Med J 2006; 23(6): 475-478. https://doi.org/10.1136/emj.2005.032672.

16. Schellein $\mathrm{O}$, Ludwig-Pistor F, Bremerich DH. Manchester triage system: Process optimization in the interdisciplinary emergency department.
Anaesthesist 2009; 58(2): 163-170. German. https://doi.org/10.1007/s00101-008-1477-9.

17. Robertson-Steel I. Evolution of triage systems. Emerg Med J 2006; 23(2): 154-155. https://doi.org/10.1136/emj.2005.030270.

18. Mistry B, Balhara KS, Hinson JS, Anton X, Othman IY, E'nouz MAL, et al. Nursing perceptions of the emergency severity index as a triage tool in the United Arab Emirates: A qualitative analysis. J Emerg Nurs 2018; 44(4): 360-367. https://doi.org/10.1016/j.jen.2017.10.012.

19. Gilboy N, Tanabe P, Travers D, Rosenau AM, Eitel DR. Emergency Severity Index, Version 4: Implementation Handbook. AHRQ Publication No.05-0046-2 ed. Rockville, MD: Agency for Healthcare Research and Quality. 2005. $95 \quad$ p. https://www.sgnor.ch/fileadmin/user upload/Dokumente/Downloads Esi Handbook.pdf.

20. Wuerz R, Milne LW, Etitel DR, Travers D, Gilboy N. Reliability and validity of new five-level triage instrument. Acad Emerg Med 2000; 16(9): 843-849. https://doi.org/10.1111/j.1553-2712.2000.tb01066.x.

21. Sacco WJ, Navin DM, Waddell RK 2nd, Fiedler KE, Long WB, Buckman RF Jr. A new resource-constrained triage method applied to victims of penetrating injury. J Trauma 2007; 63(2): 316-325. https://doi.org/10.1097/TA.0b013e31806bf212.

22. Tsai LH, Huang $\mathrm{CH}$, Su YC, Weng YM, Chaou $\mathrm{CH}$, Li WC, et al. Comparison of prehospital triage and five-level triage system at the emergency department. Emerg Med J 2017; 34(11): 720-725. https://doi.org/10.1136/emermed-2015-205304.

23. Eitel DR, Travers DA, Rosenau AM, Gilboy N, Wuerz RC. The emergency severity index triage algorithm version 2 is reliable and valid. Acad Emerg Med 2003; 10(10): 1070-1080. https://doi.org/10.1111/j.15532712.2003.tb00577.x.

24. Cooper RJ, Schriger DL, Flaherty HL, Lin EJ, Hubbell KA. Effect of vital signs on triage decisions. Ann Emerg Med 2002; 39(3): 223-232. https://doi.org/10.1067/mem.2002.121524.

25. Shelton R. The emergency severity index 5-level triage system. Dimens Crit Care Nurs 2009; 28(1): 9-12. https://doi.org/10.1097/01.DCC.0000325106.28851.89.

26. Welch S, Savitz L. Exploring strategies to improve emergency department intake. J Emerg Med 2012; 43(1): 149-158. https://doi.org/10.1016/j.jemermed.2011.03.007.

27. van Veen $M$, Steyerberg EW, Ruige $M$, van Meurs $A H$, Roukema J, van der Lei J, et al. Manchester triage system in paediatric emergency care: prospective observational study. BMJ 2008; 337: a1501. https://doi.org/10.1136/bmj.a1501.

28. Cicolo EA, Ayache Nishi F, Ciqueto Peres HH, Cruz DA. Effectiveness of the Manchester Triage System on time to treatment in the emergency department: A systematic review protocol. JBI Database System Rev Implement Rep 2017; 15(4): 889-898. https://doi.org/10.11124/JBISRIR-2016-003119.

29. Anziliero F, Dal Soler BE, Silva BA, Tanccini T, Beghetto MG. Manchester System: Time spent on risk classification and priority of care at an emergency medical service. Rev Gaucha Enferm 2017; 37(4): e64753. Portuguese, English. https://doi.org/10.1590/19831447.2016.04.64753.

30. Hunt MM, Stevens AM, Hansen KW, Fenton SJ. The utility of "trauma 1 OP" activation at a level 1 pediatric trauma center. J Pediatr Surg 2017; 52(2): 322-326. https://doi.org/10.1016/i.jpedsurg.2016.09.006.

31. Curran-Sills G, Franc JM. A pilot study examining the speed and accuracy of triage for simulated disaster patients in an emergency department setting: Comparison of a computerized version of Canadian Triage Acuity Scale (CTAS) and Simple Triage and Rapid Treatment (START) methods. CJEM 2017; 19(5): 364-371. https://doi.org/10.1017/cem.2016.386.

32. Australasian College for Emergency Medicine. Guidelines on the implementation of the Australasian Triage Scale in emergency departments. 2000; 8 p. https://acem.org.au/getmedia/51dc74f7-9ffo42ce-872a- 
0437f3db640a/G24 04 Guidelines on Implementation of ATS Jul16.aspx.

33. Cakir OD, Cevik SE, Bulut M, Guneyses O, Aydin SA. Emergency department overcrowding in Turkey: Reasons, facts and solution. JNMA J Nepal Med Assoc 2014; 52(195): 878-885. https://pubmed.ncbi.nlm.nih.gov/26982660.

34. Aksel G, Bildik F, Demircan A, Keles A, Kilicaslan I, Guler S, et al. Effects of fast-track in a university emergency department through the National Emergency Department Overcrowding Study. J Pak Med Assoc 2014; 64(7): 791-797. https://pubmed.ncbi.nlm.nih.gov/25255588.

35. Kilic YA, Agalar FA, Kunt M, Cakmakci M. Prospective, double-blind, comparative fast-tracking trial in an academic emergency department during a period of limited resources. Eur J Emerg Med 1998; 5(4): 403406. https://pubmed.ncbi.nlm.nih.gov/9919444.

36. Çinar O, Çevik E, Salman N, Cömert B. Emergency Severity Index triage system and implementation experience in a university hospital. Türkiye Acil Tıp Dergisi 2010; 10(3): 126-131. Turkish. https://turkjemergmed.com/abstract/292.

37. Ozüçelik DN, Kunt MM, Karaca MA, Erbil B, Sivri B, Sahin A, et al. A model of complaint based for overcrowding emergency department: Five-Level Hacettepe Emergency Triage System. Ulus Travma Acil Cerrahi Derg 2013; 205-214. https://doi.org/10.5505/tites.2013.44789.

38. Gural A, Banin SA, Protasov EYu, Klyuchnikov MYu. Optimization of medical care in traumatological center. Bulletin of the East Siberian Scientific Center SB RAMS 2007; (S4(56)): 57-59. Russian. https://www.elibrary.ru/item.asp?id=12293246.

39. Ghafarypour-Jahrom M, Taghizadeh M, Heidari K, Derakhshanfar $\mathrm{H}$. Validity and reliability of the Emergency Severity Index and Australasian Triage System in Pediatric Emergency Care of Mofid Children's Hospital in Iran. Bull Emerg Trauma 2018; 6(4): 329-333. https://doi.org/10.29252/beat-060410.

40. Cairós-Ventura LM, Novo-Muñoz M, Rodríguez-Gómez J, OrtegaBenítez ÁM, Ortega-Barreda EM, Aguirre-Jaime A. Validity and reliability of the Emergency Severity Index in a Spanish Hospital. Int J Environ Res Public Health 2019; 16(22): 4567. https://doi.org/10.3390/ijerph16224567.

41. Fleischmann T, Fulde G. Emergency medicine in modern Europe. Emerg Med Australas 2007; 19(4): 300-302. https://doi.org/10.1111/j.1742-6723.2007.00991.x.

42. The order of Ministry of Health from 3 July, 2017 On approval of the Rules for the provision of emergency medical care in the Republic of Kazakhstan. Kazakh 2017. https://pharmnewskz.com/ru/legislation.php/prikaz-mz-rk--450-ot-3iyulya-2017-goda 1771.

43. Semenova $Y$, Glushkova N, Pivina L, Khismetova Z, Zhunussov $Y$, Sandybaev $M$, et al. Epidemiological characteristics and forecast of COVID-19 outbreak in the Republic of Kazakhstan. J Korean Med Sci 2020; 35(24): e227. https://doi.org/10.3346/jkms.2020.35.e227.

44. Semenova Y, Pivina L, Khismetova Z, Auyezova A, Nurbakyt A, Kauysheva $A$, et al. Anticipating the need for healthcare resources following the escalation of the COVID-19 outbreak in the Republic of Kazakhstan. J Prev Med Public Health 2020; 53(6): 387-396. https://doi.org/10.3961/jpmph.20.395.

\section{Authors:}

Lyudmila Pivina - MD, Professor, Department of Emergency Medicine, Semey Medical University, Semey, Kazakhstan. https://orcid.org/00000002-8035-4866.

Assylzhan M. Messova - MD, PhD, Department of Emergency Medicine, Semey Medical University, Semey, Kazakhstan. https://orcid.org/00000001-5373-0523.

Yersin T. Zhunussov - MD, DSc, Head office, Semey Medical University, Semey, Kazakhstan. https://orcid.org/0000-0002-1182-5257.
Zhanar Urazalina - MD, PhD, Department of Emergency Medicine, Semey Medical University, Semey, Kazakhstan. https://orcid.org/0000-0002-44946565.

Zhanna Muzdubayeva - MD, PhD, Department of Faculty Therapy, Semey Medical University, Semey, Kazakhstan. https://orcid.org/0000-0002-9058$\underline{1878 .}$.

Diana Ygiyeva - MD, Master of Medicine, Department of Emergency Medicine, Semey Medical University, Semey, Kazakhstan. https://orcid.org/0000-0001-8391-8842.

Murat Muratoglu - PhD, Assistant Professor, Department of Emergency Medicine, Bashkent University, Ankara, Turkey. https://orcid.org/00000002-9586-7509.

Gulnara Batenova - MD, Department of Emergency Medicine, Semey Medical University, Semey, Kazakhstan. https://orcid.org/0000-0003-31981860.

Sharbanu Uisenbayeva - Head office, Semey Medical University, Semey, Kazakhstan. https://orcid.org/0000-0003-3198-1860.

Yulia Semenova - Professor, Head of Neurology Department, Semey Medical University, Semey, Kazakhstan. https://orcid.org/0000-0003-1324$\underline{7806 .}$ 